\title{
The Impact of the Game between Stakeholders on the Protection of Farmland
}

\author{
Fengchun Li, Weiji Zhou \\ Guangdong University of Technology, Guangzhou, China \\ Email: 646748704@qq.com
}

Received 12 September 2015; accepted 13 November 2015; published 16 November 2015

Copyright () 2015 by authors and Scientific Research Publishing Inc.

This work is licensed under the Creative Commons Attribution International License (CC BY).

http://creativecommons.org/licenses/by/4.0/

(c) (i) Open Access

\begin{abstract}
Arable land is a scarce resource with multiple values. However, the rapid development of urbanization and industrialization has posed an enormous challenge on the protection of it. This paper will first analyze three relative parties: farmers, local governments and central government. And then game theory will be used to study the behavior of these three parties so as to facilitate the conservation of farmland.
\end{abstract}

\section{Keywords}

Farmland, Protection, Farmers, Governments

\section{Introduction}

Cultivated land in China is large. However, per capita possession, the amount of quality arable land and the reserve land resource are insufficient [1]. National Land Use Change Survey showed that China's cultivated land area was 19.45 million mu (a unit of area in China) in 1998 and 18.257 million mu in 2008 (per capita availability: $1.39 \mathrm{mu}$ ), decreasing by over an average $1300 \mathrm{mu}$ each year. Due to natural and man-induced reasons, the quality of Chinese farmland is decreasing. Compared with developed countries or countries with mature agricultural industry, our grain yield is less by 150 to $200 \mathrm{~kg}$ per hectare. On top of that, under pressure of protecting and improving the ecological environment, the development of reserve land is strictly restricted. Increasing idle land and relatively backward mode of production have led to low land utilization rate. Confronted with the contradiction between people and land, the above-mentioned three parties still cannot form a strong synergy as farmers will blindly pursuit economic interests, local governments will partially emphasize on performance and the central government is unable to put forward effective policies. The writer of this paper believes that game theory will be a good method to study their behaviors and to find methods of land protection.

This paper uses game theory to analyse farmers, local governments and central government behavior seeking optimization strategy which can effectively protect the valuable farmland resources. 


\section{Stakeholders of the Farmland and Protection}

\subsection{Stakeholders}

Freeman published "Strategic Management: Analysis Approach of Stakeholder Management" in 1984 [2]. In this book he clearly put forward the theory of stakeholder management. Stakeholder management refers to the management activities carried out by the enterprise managers to balance the interests of various stakeholders. Domestic scholars, after studying the views of their predecessors, believe that stakeholders are individuals and groups who have invested in enterprise activities, borne certain risks and whose activities could affect or even change the goals of the companies or the other way around [3].

Farmland protection involves many stakeholders, while the conflicts of interests between them have hindered the conservation process. As land protection is in the public interests and due to its complexity, more and more scholars begin to introduce the stakeholder theory into the study of land protection. Stakeholder theory has helped scholars to think beyond the box and to identify more ways of land conservation. The study of stakeholders aims to find the common interests between stakeholders so as to strengthen the cooperation between them and improve the efficiency of land protection work. Three land protection stakeholders: farmers, local governments, central government are mainly studied in this paper.

\subsection{Demands of Stakeholders}

\subsubsection{Demands of Farmers}

Farmers are directly engaged in the use and protection of land. However, the role of farmers in conserving the farmland is not given full play to due to several factors, such as their education level, social status and technical methods.

Whether farmers are willing to participate in the protection of farmland mainly would depend on the following two aspects: first, land revenue. Second, improves in standards of living and quality of life. The increase of land revenue the amount of it would bear on the income of farmers, which directly impact the quality of farmers' lives. So it's easy to see that the demands of the farmers are mainly embodied by the maximization of their own interests.

\subsubsection{Demands of Local Governments}

Local governments, as the representatives of the central government, are the performer of farmland protection policy. With the deepening of economic and political reform, local governments' functions has altered from merely meeting the policy goals set by the central government to realizing the balance between certain policy goals and the maximization of reginal economic gains [4].

Local governments would mainly consider the following two aspects: first, realizing the goals and carrying out the policies of the central government. Second, the maximization of reginal land revenue. These two aspects are related to not only the performance but also the image of local governments.

\subsubsection{The Demands of the Central Government}

The central government represents the fundamental interests of our people and it guide and influence the behaviors of local governments. In the protection of farmland, the central government should consider the efficiency of three aspects. The first is economic efficiency which means achieving more with fewer inputs. The second is political benefits which aim to sustain the stability of the political situation, win the trust of the people, establish a good image and most importantly, safeguard the rights of farmers. And the third is social benefits. Agriculture is fundamental to the development of other sectors. Well-protected farmland would help ensure a balanced development between the rural and urban areas, narrow down the gap between the cities and countrysides and achieve a sustainable development of rural areas.

\section{Games between Stakeholders}

\subsection{Game Theory}

Game theory is theory and method to study phenomenon with struggle or competitive features. It is a new branch of Modern Mathematics and also an important discipline of Operations Research [5]. In 1928, von Neu- 
mann proved that the basic principles of game theory, which declared the official birth of game theory. With the evolution of game theory, game theory to study management science gradually shows its importance. Baist and Gus use the game theory to study human existence and evolution of altruistic behavior stability in economic activity [6]. Jasmina and John studied three different learning rules with the game theory to choose which performance was the best questions when imitate human behavior [7]. More and more scholars have studied management science problem to be solved from social, economic, human behavior. Game theory can help us to predict individual behavior and actual behavior, optimization strategies available to us.

Farmers, local governments and central government are the three main stakeholders of land protection. Their behaviors together determine the effect of this cause. The central government is responsible for the macro planing, organizing and supervision of land conservation. Local government is the executor of the central government policies and farmers are key participants in this activity. The central and local governments possess a dominant position in the protection of farmland, while farmers are in a low position. So on the basis of this situation, three games have formed: the game between farmers, the game between farmers and local governments and the game between the central government and local governments.

\subsection{Three Games in Farmland Protection}

\subsubsection{The Game between Farmers}

As direct users and stakeholders of arable land, the behaviors of farmers are rational. This paper would mainly analyze the features of farmers' business practices.

Participants: suppose there are only two farmers, A and B.

Model assumptions: 1) A and B have autonomy in land protection, and both are rational, aiming at the maximization of their own interests; 2) The information acquired by A and B is asymmetrical.

Strategy space: rational farming and predatory farming [8]. If A and B both chose a rational way in farming, then both sides can get some steady income, assuming 30 yuan for each of them. However, if they choose two different farming methods, assumptions that the one choosing predatory farming would get 20 yuan, the other one would get 15 yuan. If A and B both select predatory farming for short-term interests, the quality of land would definitely be severely damaged and they would each get 10 yuan as a return. I have established the game matrice between A and B as shown in Table 1.

From the above table, we can see that the game between farmers is a typical "prisoners' dilemma". Since A and $\mathrm{B}$ are unable to know each other's prior choice, predatory farming would bring more interests in a short term no matter what strategy they choose with the ultimate game-equilibrium levels at $(10,10)$. Apparently this situation will not achieve Pareto optimality.

Similarly, we assume that there are many farmers participated in this survey who are in pursuit of the maximization of their interests. Through the game, predatory peasant farming would still be their first choice. However, predatory farming is unsustainable at a time when land resources are scarce. In addition, in order to improve land yielding capability, farmers would resort to destructive means to earn more money, such as the extensive use of fertilizers and pesticides. In the long run, this will inevitably lead to land degradation, affect the revenue increase, and ultimately ruin the productivity of the land. Game between farmers would lead to unreasonable land development, impeding the process of sustainable development.

\subsubsection{The Game between Farmers and Local Governments}

Local governments, the performer of the central government policy objectives and the representatives of reginal public interests, would definitely regulate farmers' behaviors in order to improve the region's economic, political and social benefits, as well as to maximize their performances.

Participants: local governments and farmers.

Table 1. Game matrice between A and B.

\begin{tabular}{|c|c|c|}
\hline Farmer A & Rational Farming & Predatory Farming \\
\hline Rational Farming & $(30,30)$ & $(15,20)$ \\
\hline Predatory Farming & $(20,15)$ & $(10,10)$ \\
\hline
\end{tabular}


Model assumptions: 1) Both the local governments and farmers are rational. Local governments are in pursuit of best reginal performances while farmers seek to maximize short-term economic gains; 2) The two sides are unequal, and the information they can acquire is asymmetry.

Strategic choice: the strategic choice for the local government is $\mathrm{S} 1=$ oversee, overlook $\}$ while farmers' strategic choice would be $\mathrm{S} 2=$ \{protect and not to protect $\}$. The two sides would form four kinds of game strategy, namely \{oversee, protect $\}$, \{oversee, not to protect\}, \{overlook, protect\}, \{overlook, not to protect .

Utility function: 1) The local governments take regulatory strategy while farmers protect arable land. The total cost of the local government is assumed to be C, composed by the regulatory costs C1 and other input costs $\mathrm{C} 2$, such as water conservancy infrastructure construction, science and technology education, subsidies etc. Assuming that local government revenue is R, composed by the central government subsidies or incentives R1 and other farmland protection outputs R2. The input of farmers to protect farmland is assumed to be I, and gain to be $\mathrm{K}$, composed by the land revenue $\mathrm{K} 1$ and other income such as subsidies $\mathrm{K} 2$. At this time, the utility combination would be (R-C, K-I) or (R1 + R2-C1-C2, K1 + K2-I). 2) Local governments take regulatory strategy while farmers do not protect farmland. Assuming that local governments regulatory costs is $\mathrm{C}$, and revenue is composed by central government subsidies R1 and the fines A. Farmers' predatory farming income is assumed to be M. In this case, the utility would be (R1 + A-C, M-A). 3) Local governments don't take regulatory strategy while farmers protect arable land. At this point local governments do not need to pay the cost of land protection and their revenue stands at R. The inputs of farmers would still be I, and gains, K1 with no subsidies and other income. In this case, the utility would be (R, K1-I) or (R1 + R2, K1-I). 4) Local governments don't take regulatory strategy and farmers do not protect farmland. In this case, the governments do not need to pay the cost of land protection and their revenue is still R. Predatory farming income would be M. However, this behavior is bound to incur great political, economic and social losses, borne by the governments and farmers respectively (the cost shouldered by them would be L1 and L2 respectively). In this case, the utility would be (R1 + R2-L1, M-L2). Local governments and farmers game model is as shown in Figure 1.

We can see from the Figure 1 that whether local governments take regulatory strategy depends largely on the affirmation of performance, and regulatory costs and benefits. And whether farmers would protect arable land depends primarily on land revenue and other incomes, such as government subsidies. But as China is a relatively backward in the development of agricultural sector, the local governments would need to pay a high coast when carrying out regulatory strategies. And at the same time if the governments regulation is too tight, farmers would be left with two options: the first one is to give up land and the second one is to take predatory farming practices so as to maximize revenue. As the cost is high for farmers to protect land and government subsidies are also too limited, the local governments would tend to give up supervision. This situation is bound to bring bad effects for the region's political, economic and social development. And at the same time, as those negative effects would not reveal itself in a short term, neither the farmers nor local governments would like to take up risks. Therefore, local governments and farmers' strategic choice is \{overlook, not to protect\}.

\subsubsection{The Game between the Central Government and Local Governments}

Local governments play a dual role in the protection of farmland. They are both the representative of public interests and the pursuer of reginal interests. They represent public interests as they are the branches of the central government and pursuing reginal interests depends on their jurisdiction and power limitations. As we can see from Figure 1 that local governments, when not receiving dictations from the central government, would do everything to avoid risks. Their overlook over land protection is would hinder long-term and sustainable development. It is necessary to establish a game model between local governments and the central government.



Figure 1. Local governments and farmers game model. 
Participants: the central government and local governments.

Model assumptions: 1) The rationality of the central government and local governments is limited; 2) The behaviors of the parties depend on the costs and benefits; 3) Local governments overbeat the central government in the acquisition of information.

Strategic choice: The central government's strategy choice is $\mathrm{S} 1=$ \{supervise, not to supervise $\}$. Local government's strategic choice is S2 = \{execute, not to execute $\}$. The two sides form four kinds of game strategy, namely \{supervise, execute\}, \{supervise, not to execute\}, \{not to supervise, execute\}, \{not to supervise, not to execute\}.

Utility function: the central government's regulation costs is recorded as C, the costs caused for the society, the economy and the ecological environment are recorded as L. The fine that the local government refuse to execute strategy is A while the income of the local government failing to execute strategy is $R$. Moreover, the possibility of the central government adopting policy supervision is $p$, while the possibility of the local government choosing not to enforce the policy is $q$. The central government and local governments game matrix is as shown in Table 2.

When local governments enforce strategies, the revenue expectation in this mixed condition is:

$$
\begin{gathered}
{[0 \cdot p+0 \cdot(1-p)]+[-A \cdot p+\mathrm{R} \cdot(1-p)] \cdot q=0} \\
p^{*}=\mathrm{R} /(\mathrm{A}+\mathrm{R})
\end{gathered}
$$

When the central governments take oversight strategy, the return would be:

$$
\begin{gathered}
{[-\mathrm{C} \cdot(1-q)+(\mathrm{A}-\mathrm{L}-\mathrm{C}) \cdot q] \cdot p+[0 \cdot(1-q)+(-L) \cdot q] \cdot(1-p)=0} \\
q^{*}=\mathrm{C} /(\mathrm{A}-\mathrm{L} / p)
\end{gathered}
$$

The results show that the Bayesian Nash equilibrium is: $p^{*}=\mathrm{R} /(\mathrm{A}+\mathrm{R}), q^{*}=\mathrm{C} /(\mathrm{A}-\mathrm{L} / p)$ under the mixed strategy with $p$ inversely proportional to $q$ and $p$ in direct proportion to $1-q$. In other words, the strength of the central government's supervision is in direct proportion to the enforcement of the local government. In addition, the higher the supervision costs $C$, the greater the possibility $q$ which means that the higher the likelihood of the local governments choose not to enforce policies. The other way around, the more severe of the punishment when the local governments fail to enforce strategies, the lower the possibility $q$ and the higher the likelihood of the local governments to adopt central government policies.

\section{Conclusions}

\subsection{The Concepts Dimension}

Farmers, as a separate business entity, aim to pursue the maximization of their own interests. Farmers' lack of enthusiasm in protecting farmland can be partly attributed to the influence of traditional concepts. Therefore, their concepts must be changed. First, it is imperative that farmers do recognize the importance of agriculture, in particular the significance of land conservation. We must makes farmers stop feeling that the protection of arable land is irrelevant. Second, we must let farmers believe that active farming would bring tangible benefits for them and this would require government policies and the market. Farmers have to be ensured that rational farming would also improve their standard of living and quality of life.

Local government and the central government, as the defenders of public interests need to set correct performance views. While boosting urban and rural development, they should also try to achieve the coordination of

Table 2. The central government and local governments game matrix.
\begin{tabular}{ccc}
\hline Local governments & Execute $(1-q)$ & Not to execute $(q)$ \\
The central governments & $(-\mathrm{C}, 0)$ & (A-L-C, $-\mathrm{A})$ \\
\hline Supervise (p) & $(0,0)$ & $(-\mathrm{L}, \mathrm{R})$ \\
Not to supervise $(1-\mathrm{p})$ & &
\end{tabular}


economic, ecological, and social wellbeing; they should cultivate strategic vision and set long-term targets instead of being confined to limited short-term interests. They should also set an overall concept and learned to view problems with a holistic approach. They should also establish communication channels between the local and the central governments, so as to share information and make policies more efficient, relevant and practical.

\subsection{The Institutional Dimension}

\subsubsection{Creating New Supervision Mechanisms}

Cultivated land protection supervision should be realistic. Through the game between the local governments and the central government's, we know that the supervision of the central government and the enforcement of the policies by the local governments is positively correlated. In addition, the higher the supervision costs, the greater the possibility of local governments not to implement the policies. The more the penalties severe, the higher the possibility of them enforce the policies.

Therefore, we must strike a balance among the oversight, supervision costs and penalties. A more transparent information exchanging channel must be established so as to reduce monitoring costs. The authorities should find an appropriate balance between rewards and punishments to fully mobilize various forces and improve the motivation and efficiency of cultivated land protection work. We can also start a land conservation group and regularly conduct surveys over the cultivated land protection work at the local levels so as to ensure the enforcement.

\subsubsection{Creating New Compensation Mechanism for Cultivated Land}

Cultivated land compensation is one source of farmers' income, and they are playing an increasingly important role. In the game between farmers and local Governments, arable land compensation directly affects the strategic choice of the farmers. To create new compensation mechanism for cultivated land, we should first determine the receiver of the compensation. Strict subdivision is the base for land compensation innovation. Secondly, we must determine arable land compensation standard scientifically, using the economic value of reservation utility of arable land as the assessment. The protection of arable land should be connected with the market. Thirdly, we should identify new channels to invite land protection funds. such as new construction land use fees, the transfer income for the development of land of agricultural use and the reclamation fee of arable land, and social donor investment etc. Fourthly, we should explore suitable arable land protection compensation ways. We can establish non-profit arable land protection foundation leaded by local governments, local professional private institutions, farmer representatives and rural professional cooperatives using city, county and district as units. At last, we should also explore ways to ensure the enforcement of arable land compensation. We should establish incentive, constraint mechanism, and guarantee mechanisms which are closely linked together to ensure the effectiveness of the compensation.

\subsubsection{Creating New Land-Revenue Accounting Standards}

Farmers' land revenue would heavily influence their decisions. Therefore, cultivated land resource value, asset value, social and ecological value of farmland should be comprehensively accounted. Land quality, location, cultivation conditions, scarcity, crop yielding rate as well as the level of local economic development should be evaluated as a way to guarantee farmers' incomes and moderately high quality of life.

\section{References}

[1] Tang, R. (2009) Present Situation and Utilization Policies of Cultivated Land Resources in China. Modern Agricultural Science and Technology, 12.

[2] Freeman (1984) Strategic Management: Analysis Approach of Stakeholder Management. Cambridge University Press, Cambridge.

[3] Jiang, R.M. and Jin, Y.H. (2009) Corporate Stakeholder Theory and Application. Peking University Press.

[4] Fu, S.Y. (2011) Characteristics and Prospect of the Transformation of Government Functions in China.

[5] Zhang, L.Q. and Feng, C.W. (2001) Rationality and Bounded Rationality: Classical Game Theory and Evolutionary Game Theory. The World Economy, 8.

[6] Bester, H. and Guth, W. (1998) Is Altruism Evolutionarily Stable? Journal of Economic Behavior \& Organization, 34. 
[7] Jasmina, A. and John, L. (2004) Scaling up Learning Models in Public Good Games. Journal of Public Economic Theory, 6.

[8] Zheng, L.J. (2012) Interests Coordinating Mechanism Building of Cultivated Land Protection in China. Master's Thesis, Fujian Normal University. 